\title{
NOTES TO READERS
}

During the long course of writing this book, we have adopted several conventions that may differ from other scientific publications, and they are explained here.

\section{Acronyms}

Throughout this book we follow the migration routes and evolutionary interactions of various Cannabis gene pools and their representative taxa. For clarity and readability we represent these gene pools with acronyms such as BLH, rather than broad-leaf hemp or Cannabis indica ssp. chinensis. Full names are used when they first appear in each chapter, and readers should refer often to Table 1 , which lists the acronyms used in this book.

\section{Place Names}

The time frame of this book stretches from prehistory into the future. Geographical and political names have changed repeatedly during the historical period and are likely to do so again. We have chosen to use the names and political boundaries of present-day countries and regions, even though they may not have been used in the past since this seems easier for the reader than switching names and boundaries during each time period. Geographical terms are the most recently accepted Roman character versions of foreign terms, many of which have only recently come into common Western usage, such as the "Hengduan Mountains" and "Yungui Plateau" of southwestern China. We also choose to capitalize geographical features such as Yangzi River but not to capitalize political designations such as Sichuan province.

\section{Spelling}

We use Roman character versions of foreign words and phrases familiar to those who predominately read English. Most Chinese words in the text are presented in modern-day Pinyin without diacritical marks, as well as translated to English, and simplified Chinese characters and Pinyin versions with diacritical marks are included for particularly important terms or where linguistic connections would be less clear without them. We capitalize Chinese and Korean dynasty names as well as historical periods and geological eras and epochs.

\section{Dates}

In a modern cross-cultural treatise for readers from diverse religious and historic backgrounds, we feel it is appropriate to use в Се (before the Common Era) rather than в (before Christ), and CE (of the Common Era) rather than AD (anno Domini, "in the year of the Lord"). Dates B CE are noted as such, as are early dates CE (generally before $1000 \mathrm{CE}$ ), and after this time the epithet is dropped as in 1492 or 2010. For geological time spans and most archeological data, we choose to use в р (before the present) rather than the date (в С Е оr СЕ) so the reader will understand how long ago things happened. We make an exception when referring to historical dynastic eras, where we use dates.

\section{Photographs}

All photos in this book were taken by Robert C. Clarke unless otherwise noted. 